\title{
EFFECTS OF THYROPARATHYROIDECTOMY ON IMPLANTATION AND EARLY GESTATION IN RATS
}

\author{
SAMARENDRA N. BAKSI* \\ Worcester Foundation for Experimental Biology, \\ Shrewesbury, Massachusetts 01545, U.S.A.
}

(Received 11th August 1972)

It has been demonstrated that thyroxine is essential for normal fertility in rats and rabbits (Chu, 1944-46; Krohn \& White, 1950); a study by Parrott, Johnston \& Durbin (1960) included parathyroid hormone (PTH) as well as thyroxine $\left(\mathrm{L}-\mathrm{T}_{4}\right)$. The present preliminary study was undertaken to investigate whether thyrocalcitonin (TCT) and PTH have any influence on implantation and early gestation in rats.

Thirty, 2-month-old, female Charles River rats (Charles River Breeding Laboratory, Waltham, Mass.) with an average body weight of $208 \mathrm{~g}$ were randomly allocated to six equal groups. They were housed in an air-conditioned room, exposed to $14 \mathrm{hr}$ of light and had free access to Purina lab pellets and tap water. On the 1st day of pregnancy (the day when spermatozoa were detected in vaginal smears after the females were placed overnight with males of proven fertility), five groups were thyroparathyroidectomized according to the method described by Hirsch, Gauthier \& Munson (1963). The rats in the remaining group were subjected to sham operation and served as the controls. Replacement studies were initiated after the operations.

Thyroxine (synthetic sodium L-thyroxine, Flint Laboratories) and parathyroid extract (Eli Lilly \& Co.) were dissolved and diluted, respectively, with normal saline. Thyrocalcitonin (calcitonin, Armour Pharmaceuticals) was dissolved in acidic saline adjusted to $\mathrm{pH} 4.5$ with dilute hydrochloric acid. The respective doses of $\mathrm{L}-\mathrm{T}_{4}, \mathrm{PTH}$ and TCT were $2.5 \mu \mathrm{g}, 15 \mathrm{USP}$. U and 50 MRC $\mathrm{mU} / 100 \mathrm{~g}$ body weight. Injections of PTH and TCT were given twice daily until the 13th day of gestation. All drugs were administered subcutaneously in a volume of $0.1 \mathrm{ml}$. An equal volume of acidic saline was used as the control injection.

On Day 7 of gestation, the number of implants (beads) in both horns of the uterus was recorded for each animal at laparotomy under ether anaesthesia. The animals were returned to individual cages after the abdominal muscles were sutured with fine silk thread and the skin closed by a wound clip. On Day 14, the animals were similarly anaesthetized and the numbers of embryos in the uteri were recorded. Blood samples were taken from the abdominal aorta in each rat and stored in centrifuge tubes under ice. The animals were then killed by opening the diaphragms. Embryos were dissected out individually, with

\footnotetext{
* Present address: National Institute of Environmental Health Sciences, Pharmacology and Toxicology Branch, P.O. Box 12233, Research Triangle Park, North Carolina 27709, U.S.A.
} 


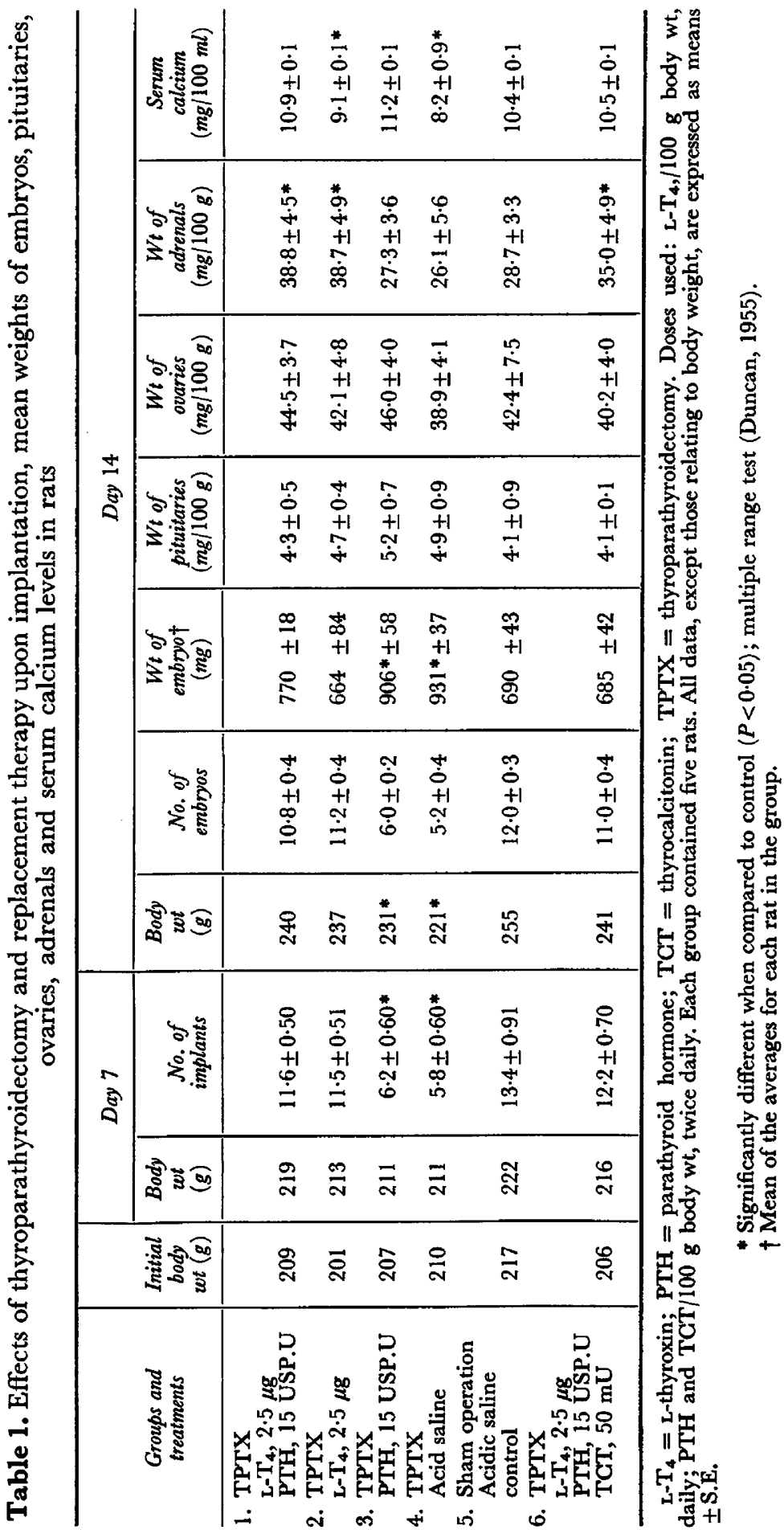


the intact amniotic sac and a portion of the uterine wall, and weighed. Adrenals, ovaries and pituitary glands were removed, freed from fat and weighed.

Calcium was estimated by diluting $0.2 \mathrm{ml}$ serum with $9.8 \mathrm{ml}$ diluting fluid $(0.1 \%$ Lanthanium in $0.06 \mathrm{~N}-\mathrm{HCl})$ and analysed in a Perkin-Elmer Atomic Absorption Spectrophotometer Model 290B (Perkin-Elmer Corp., 1971).

The results presented in Table 1 demonstrate that TCT as well as PTH had no apparent effect on implantation and early gestation up to Day 14. The numbers of implants in TCT- and/or PTH-deficient rats (Groups 1 and 2) were not different from the controls or other treated groups, except for Groups 3 and 4 in which $\mathrm{L}-\mathrm{T}_{4}$ was not administered. Serum calcium levels in the PTHdeficient groups $(2$ and 4$)$ were lower $(P<0.05)$ than control or PTHreplacement groups. The dose of PTH used in this experiment was sufficient to keep the calcium level of blood within a normal physiological range. The apparent hypocalcaemia observed in the PTH-deficient groups had no visible effect on implantation processes and the early development of embryos. The severity of PTH deficiency was more apparent in Group 4 in which $\mathrm{L}_{-} \mathrm{T}_{4}$ was also lacking. In those groups ( 3 and 4 ) lacking $L-T_{4}$, the number of implants was significantly lower $(P<0.05)$ when compared to the controls and all other groups. Though the number of implantation sites was reduced in the $\mathrm{L}^{-\mathrm{T}_{4}}$ deficient groups, the mean weight of embryos on Day 14 was higher $(P<0.05)$ when compared to the controls and other groups. This might have been due to the fact that as the number of developing embryos in the uterus decreased, their weights increased as a result of better nourishment (Wilson, Runner \& Zarrow, 1963).

Pituitary and ovarian weights in the control and treated groups did not change, but adrenal weights in groups given $\mathrm{L}-\mathrm{T}_{4}(1,2$ and 6$)$ increased significantly $(P<0.05)$ when compared to the control, thyroparathyroidectomized and $\mathrm{PTH}$ groups $(3,4$ and 5$)$. Exogenous $\mathrm{L}_{-} \mathrm{T}_{4}$ probably triggered ACTH release in these animals (Contopoulos \& Koneff, 1963). The body weights of Groups 3 and $4\left(\mathrm{~L}-\mathrm{T}_{4}\right.$-deficient) decreased significantly $(P<0.05)$ on Day 14 when

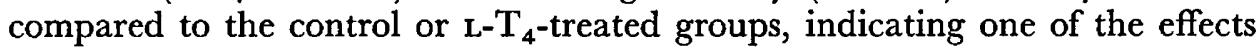
of hypothyroidism in rats.

This investigation was carried out while the author was a Postdoctoral Fellow in the Physiology of Reproduction (Dr C. W. Lloyd, Program Director) supported by NICHD Training Grant HD 00282. The author wishes to express his thanks to Dr J. P. Aldred and Dr R. J. Hosley of Armour Pharmaceutical Co., Kankakee, Illinois, and Lilly Research Laboratory, Eli Lilly \& Co., Indianapolis, Indiana, for generous gifts of the thyrocalcitonin and parathyroid extracts used in this study.

\section{REFERENCES}

CHU, J. P. (1944-46) The influence of the thyroid on pregnancy and parturition in the rabbit. $\mathcal{F}$. Endocr. 4, 109.

Contopoulos, A. N. \& Konefr, A. A. (1963) Pituitary hormone production and release in the thyroidectomized rat after thyroxine administration. Acta endocr., Copenh. 42, 275.

Duncan, D. B. (1955) New multiple range and multiple F tests. Biometrics, $1,1$. 
Hirsch, P. F., Gauthier, G. F. \& Munson, P. L. (1963) Thyroid hypocalcaemic principle and recurrent laryngeal nerve injury as factors affecting the response to parathyroidectomy in rats. Endocrinology, 73, 244.

KRohn, P. L. \& White, H. G. (1950) The effect of hypothyroidism on reproduction in the female albino rat. F. Endocr. 6, 375.

Parrott, M. W., Johnston, M. E. \& Durbin, P. W. (1960) The effects of thyroid and parathyroid deficiency on reproduction in the rat. Endocrinology, 67, 467.

Perkin-Elmer Corporation (1971) Analytical methods for atomic absorption spectrophotometry. PerkinElmer Corp., Norwalk, Conn.

Wilson, E. D., Runner, M. N. \& Zarrow, M. X. (1963) Effect of hypothyroidism, diet and litter size on superovulation in the mouse and rat. 7. Reprod. Fert. 5, 233. 